\title{
The effect of artificial weathering on PP coextruded tape and laminate
}

\author{
Lucia Marsich $^{\mathrm{a}, *}$, Alessio Ferluga ${ }^{\mathrm{a}}$, Luca Cozzarini ${ }^{\mathrm{b}}$, Marco Caniato ${ }^{\mathrm{a}}$, Orfeo Sbaizero ${ }^{\mathrm{a}}$, Chiara Schmid ${ }^{\mathrm{a}}$ \\ ${ }^{a}$ Department of Engineering and Architecture, University of Trieste, Via A. Valerio 6/A, 34127 Trieste, Italy \\ ${ }^{\mathrm{b}}$ MaterialScan S.r.l., Via A. Valerio 6/A, 34127 Trieste, Italy
}

\section{A R T I C L E I N F O}

\section{Article history:}

Received 14 October 2016

Received in revised form 30 December 2016

Accepted 20 January 2017

Available online 21 January 2017

\section{Keywords:}

A. Polymer (textile) fibres

B. Environmental degradation

D. Surface analysis

D. Thermal analysis

\begin{abstract}
A B S T R A C T
The aim of this work was to analyse the influence of artificial weathering on polypropylene (PP) selfreinforced composite both as fabric constituent (tape) and as laminate. Particular attention has been focused on the interaction between radiation and material microstructural characteristics, especially for the selective action that the former causes in PP amorphous regions. The evaluation of carbonyl index performed by Fourier Transform Infrared (FT-IR) spectroscopy has highlighted that tapes are more prone to degradation since their drawn structure induces internal stress. Differential scanning calorimetry (DSC) measurements have denoted a shift towards lower temperature of PP melting peak. While crystallinity determination performed by DSC and FT-IR spectroscopy has underlined an increasing trend for laminate over exposure time due to the higher amount of amorphous phase, Raman spectroscopy has revealed that photo-degradation induces a rise of the isomeric defect fraction, limiting chemicrystallisation both for tapes and laminates.
\end{abstract}

(c) 2017 Elsevier Ltd. All rights reserved.

\section{Introduction}

Thermoplastic composite investigation is one of the most explored research fields since manufacturers are interested to gain materials with superior characteristics in terms of mechanical resistance and reduced weight. In order to introduce innovative products on the market, many studies have been conducted on polypropylene based Self-Reinforced Composites (SRCs) which seems to be a promising material class for several industrial applications $[1,2]$.

Several manufacturing processes have been reviewed in literature $[1,2]$, but one of the most attractive production technologies is tape coextrusion. Coextruded tapes, composed of high stretched polypropylene (PP) homopolymer core and lower melting temperature polypropylene/polyethylene copolymer (coPP/PE) skin, have been widely studied [3-5] in order to evaluate how drawing process affects material characteristics. Particular attention has been paid to the influence of consolidation parameters on laminate mechanical properties [6,7] and impact resistance [8].

Since SRCs can be designed for outdoor applications, the influence of atmospheric agents on final performance has to be considered. Many factors such as heat and oxygen [9-11], water absorption [12] and low temperature [13] play a key-role in PP degradation mechanisms, but the most aggressive agent is the ultraviolet radiation.

\footnotetext{
* Corresponding author.

E-mail address: lmarsich@units.it (L. Marsich).
}

The effects of photo-oxidation on polyolefin (both PP homopolymer and coPP/PE) have been already studied in literature. A rapid decrease of tensile strength can be observed in PP injection moulded samples at different exposure time [14,15] and in PP filament yarns subjected to natural and artificial weathered conditions [16]. Similarly, the Young's modulus of PP extruded plates decreases with exposure time as a consequence of crack formation on material surface [17].

Different techniques have been used to study degradation mechanisms through the detection of low molecular by-products formed during reactions. Typical functional groups, such as hydroxyl $(\mathrm{OH})$, hydroperoxide $(\mathrm{OOH})[18]$ and in particular carbonyl $(C=0)[19,20]$, have been identified by FT-IR. On the other hand, Raman spectroscopy is more suitable for vinyl groups $\left(-\mathrm{CH}=\mathrm{CH}_{2}\right)$ determination [21,22] and for the creation of spectral maps on microscopic scale in order to define species distribution on sample surface [23].

Chain scission and crosslinking rates have been determined for thermoplastics (polypropylene, polyethylene and copolymer) by means of gel permeation chromatography [24]. It has been noted that reaction rates are very effective near material surface, whereas they significantly decrease through the bars due to scarce oxygen concentration (oxygen diffusion limited reaction). The same outcomes have been found elsewhere [25], where comprehensive information on the modifications induced by outdoor aging on coPP/PE are provided.

The effect caused by natural aging on isotactic polypropylene (i-PP) has been analysed by means of Differential Scanning 
Calorimetry (DSC) and Thermogravimetry (TG) in order to evaluate crystallisation heat variations [16]. Material characteristics, such as crystallinity and spherulite size, influence photo-oxidation rate [26]: in particular higher crystallinity fraction leads to slower degradation rate. During artificial weathering a crystallinity increase can be observed due to chemi-crystallisation, a mechanism that induces molecular reorganisation in PP amorphous phase [27], with a subsequent melting enthalpy rise. Furthermore, for samples recrystallised under non-isothermal conditions, longer exposure time results in (i) crystallinity fraction reduction, (ii) fusion peak duplication and (iii) melting temperature decrement, due to impurities, reorganisation during heating and low molecular weight formation (chain scission) respectively [28].

Some authors $[29,30]$ have studied the synergistic effect of stress and UV irradiation on PP. The results have shown that both chain scission and crosslinking occur on material surface and their concentration increases accordingly to tensile stress [29].

Slow strain rate tensile test performed on notched samples have revealed that cracking and chemical degradation are enhanced by stress concentration in the notch-surrounding area. Furthermore, sample mechanical properties are reduced if UV irradiation has been applied during tensile test [30].

In the field of SRCs a preliminary study has been conducted to determine qualitatively the difference in matrix and reinforcement after weathering by means of Raman spectroscopy [31].

This work aims to evaluate UV effect on coextruded tape and laminate for a possible outdoor application. SRC mechanical properties as a function of exposure time have been already investigated in a previous work [31], where a significant decrease of mechanical properties and an evident embrittlement after $250 \mathrm{~h}$ have been highlighted.

In this study particular attention has been focused on the interaction between radiation and the highly drawn microstructure of this material class. After a visual inspection, DSC, FT-IR and Raman spectroscopy have been applied to quantify the degradation, measuring melting temperature, carbonyl index and crystallinity.

\section{Materials and methods}

A commercial plain weave fabric has been selected for the present work. The fabric has an overall weight of $107 \mathrm{~g} / \mathrm{m}^{2}$ and it is composed of coextruded PP tapes $2.5 \mathrm{~mm}$ wide with a linear density of 1300 dTex. The fabric has the same number of tapes arranged in warp and weft direction, with $\mathrm{C}: \mathrm{H}: \mathrm{C}$ tape crosssection configuration, where the skin $C$ is coPP/PE + PE blend and $H$ is the oriented PP homopolymer. Ten fabric layers have been positioned between $300 \times 300 \mathrm{~mm}$ hot plates and samples have been consolidated at $140{ }^{\circ} \mathrm{C}$ and $2.2 \mathrm{MPa}$, as suggested by manufacturer's specifications.

\subsection{Artificial weathering}

A Q-Sun Xenon test Chamber Model Xe-1 manufactured by QLAB, equipped with a xenon-arc lamp, which emits radiation from ultraviolet to infrared, has been used for accelerated aging. A daylight filter has been applied in order to produce a spectral power distribution (SPD) of $678.8 \mathrm{Wm}^{-2}$ in the range $300-800 \mathrm{~nm}$ equivalent to noon summer sunlight. An irradiance sensor and an insulated black panel temperature sensor, both embedded in the chamber, control the wavelength in the range $340 \pm 10 \mathrm{~nm}$ and the temperature, respectively. The exposure parameters used during artificial weathering test have been chosen in accordance with ISO 4892-part 2.

\subsection{Differential Scanning Calorimetry (DSC)}

Differential Scanning Calorimetry (DSC) has been performed with a Netzsch DSC 200 F3 Maia ${ }^{\circledR}$ differential scanning calorimeter. $5 \mathrm{mg}$ samples, obtained randomly both from tape and consolidated laminates, placed within closed aluminium crucibles, have been heated from room temperature to $200{ }^{\circ} \mathrm{C}$ with a heating rate of $10{ }^{\circ} \mathrm{C} \mathrm{min}^{-1}$. Three samples have been measured for each test performed. DSC traces have been analysed with Netzsch Proteus Thermal Analysis - Version 6.1.0.

\subsection{Raman spectroscopy}

An InVia Raman microscope (Renishaw plc., Wotton-UnderEdge, UK) has been used to acquire all Raman spectra. The laser (785 $\mathrm{nm}$ diode laser delivering $250 \mathrm{~mW}$ to the sample) has been focused by a microscope objective $(10 \times$ N.A. 0.25$)$ onto the sample. Six spectra have been collected randomly around the samples with an acquisition time of $30 \mathrm{~s}$.

Spectra have been analysed using hyperSpec [32], a package of the R software for statistical analysis [33] and Fityk 0.9.8 [34] fitting the vibrational bands with Voigt function. The fraction of the crystalline phase $\left(X_{c}^{\text {Raman }}\right)$ and the isomeric defect phase $\left(X_{b}^{\text {Raman }}\right)$ have been evaluated using the method described by Nielsen [35].

\subsection{FT-IR spectroscopy}

Three FT-IR spectra of each sample have been collected between 400 and $4000 \mathrm{~cm}^{-1}$ using a Thermo Nicolet Nexus 470 FTIR with Avatar Diffuse Reflectance accessory. The nominal resolution of the spectrometer has been $2 \mathrm{~cm}^{-1}$, averaging 120 scans. Samples have been prepared using a Silicon carbide sampling kit.

As for Raman spectroscopy, spectra have been analysed using hyperSpec [32], a packages of the R software for statistical analysis [33] and Fityk 0.9.8 [34] fitting the vibrational bands with Voigt function.

The crystalline phase fraction $\left(\mathrm{X}_{\mathrm{c}}^{\mathrm{FT}-\mathrm{IR}}\right)$ has been evaluated using the method described by Karacan [36]. Following the work of Rabello [26,27] and Aslanzadeh [18], the Carbonyl Index $\left(\mathrm{CI}^{\mathrm{FT}-\mathrm{IR}}\right)$ has been evaluated as the ratio between the area of the absorbance band in the range of $1650-1850 \mathrm{~cm}^{-1}$ and the area of the absorbance band in the region of $2694-2750 \mathrm{~cm}^{-1}$.

\section{Results and discussions}

Fig. 1 shows laminate and tape exterior morphology before irradiation and after $500 \mathrm{~h}$ of exposure.

As it can be noticed, tape and laminate show negligible defects, probably caused by manufacturing process; conversely, laminate surface exposed to radiation is characterized by the presence of cracks, which are more evident and widely distributed than on tape.

This fact can be explained by chemi-crystallisation, a mechanism that involves molecular reorganisation only in the amorphous regions of the polymer (higher for laminate due to consolidation process), that causes spontaneous crack formation due to surface layer contraction [27].

\subsection{FT-IR and Raman spectroscopy}

Fig. 2 depicts typical FT-IR spectra of laminate and tape after different irradiation periods.

After irradiation the main spectral changes occur in the region between 1650 and $1850 \mathrm{~cm}^{-1}$, where the characteristic peaks associated to carbonyl group vibrations appear and increase for longer exposure times. After $250 \mathrm{~h}$, another broad band between 3250 

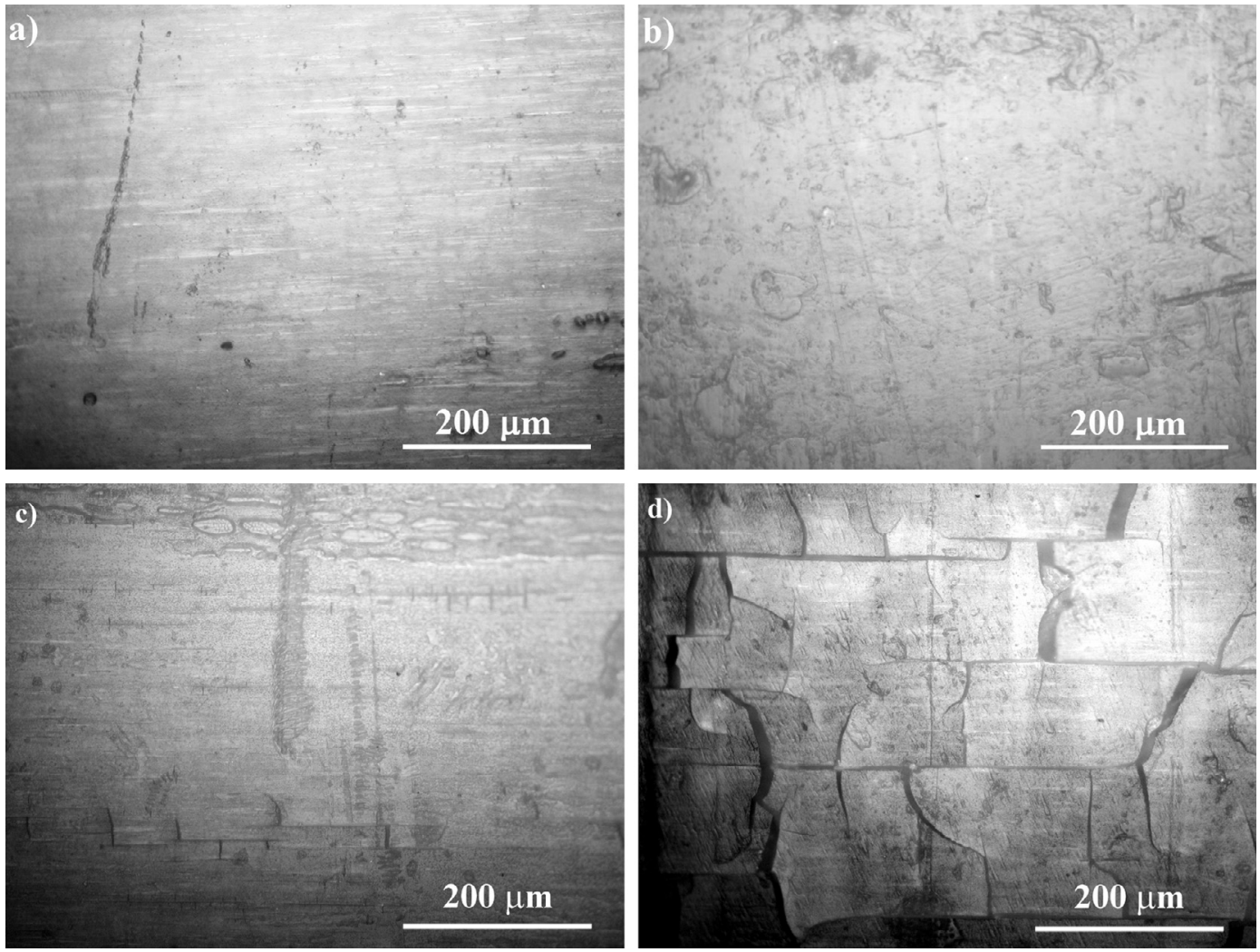

Fig. 1. Surface morphology of tape and laminate: before irradiation (a) and (b), after $500 \mathrm{~h}$ of exposure (c) and (d).
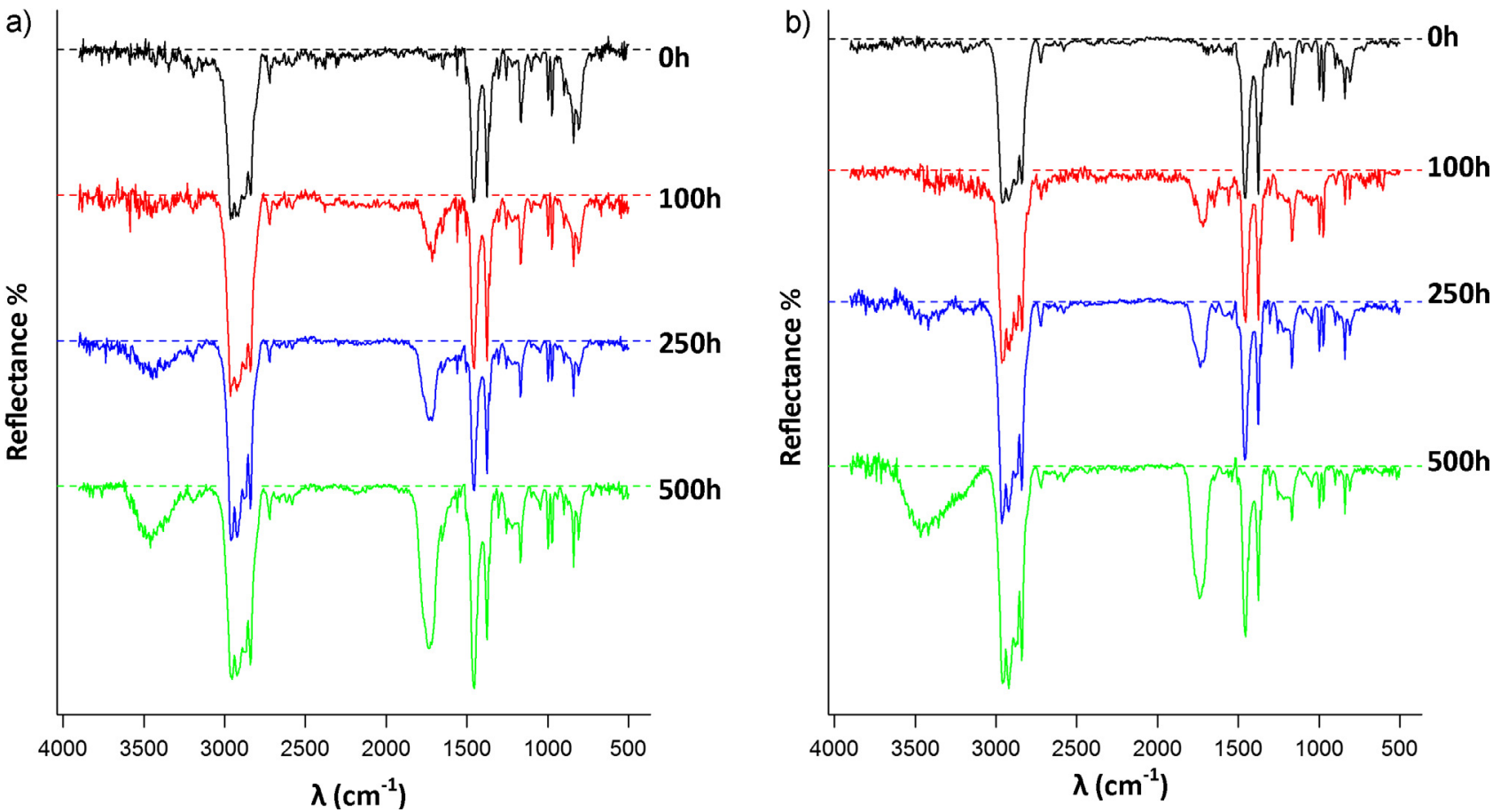

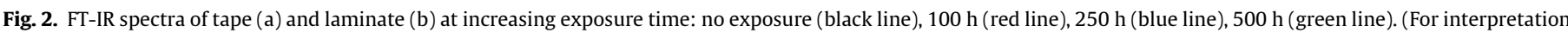
of the references to colour in this figure legend, the reader is referred to the web version of this article.)

and $3600 \mathrm{~cm}^{-1}$, corresponding to hydroxyl and/or hydroperoxide group vibrations [18], appears and its intensity increases up to $500 \mathrm{~h}$.
As expected, Raman spectra do not show any changes in the region between 1650 and $1850 \mathrm{~cm}^{-1}$ due to Raman spectroscopy selection rules [23]. But, as reported in previous work [37], Raman 
spectroscopy is able to highlight the presence of PE vibrational bands, both in tape and laminate spectra.

Carbonyl Index $\left(\mathrm{CI}^{\mathrm{FT}-\mathrm{IR}}\right)$ has been calculated both for laminate and tape, following the work of Rabello [26,27] and Aslanzadeh [18], in order to quantify carbonyl group formation over time.

As expected, both laminate and tape $\mathrm{CI}^{\mathrm{FT}-\mathrm{IR}}$ increases with exposure time (Fig. 3). For tape, $\mathrm{CI}^{\mathrm{FT}-\mathrm{IR}}$ values are higher already after $100 \mathrm{~h}$ and $250 \mathrm{~h}$ of exposure, probably because of a synergistic effect of chemical degradation and tape internal stress induced by drawing process [30]. Conversely to tapes, laminates are less susceptible to chemical degradation because consolidation partially removes those internal stresses.

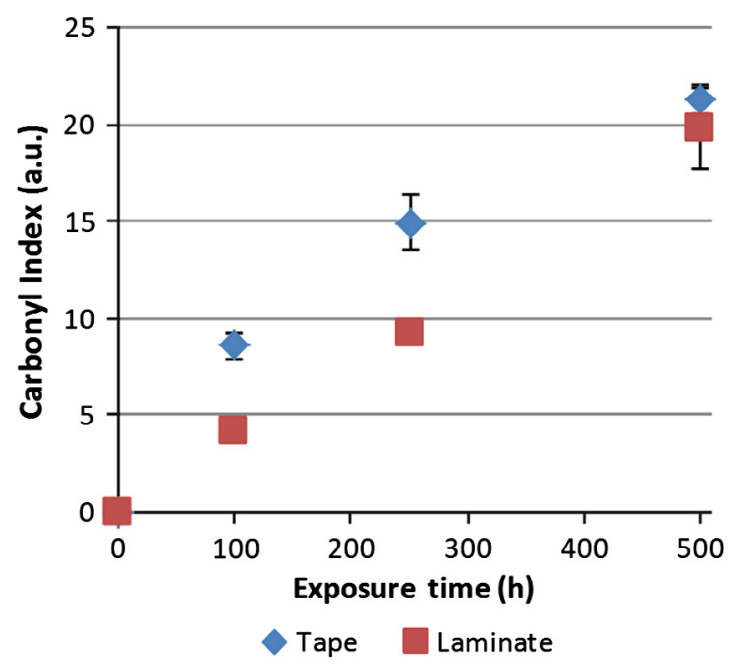

Fig. 3. $\mathrm{CI}^{\mathrm{FT}-\mathrm{IR}}$ as a function of exposure time. (For interpretation of the references to colour in this figure legend, the reader is referred to the web version of this article.)

\subsection{Differential Scanning Calorimetry (DSC)}

Fig. 4 summarises laminate and tape DSC traces at increasing exposure time. As reported in previous work [37], melting thermograms of both tape (Fig. 4a, black line) and laminate (Fig. 4b, black line) samples showed distinct melting peaks for PE $\left(107^{\circ} \mathrm{C}\right)$ and PP (between 140 and $170{ }^{\circ} \mathrm{C}$ ); after data fitting, three melting peaks for PP during first heating have been identified.

Tape main melting peak temperature $\left(166^{\circ} \mathrm{C}\right)$ appears to be stable up to $100 \mathrm{~h}$ of irradiation. After $250 \mathrm{~h}$ and $500 \mathrm{~h}$ (Fig. 4a, blue and green curves) main melting peak shifts toward lower value, about $158{ }^{\circ} \mathrm{C}$ and $153{ }^{\circ} \mathrm{C}$ respectively, while a small melting peak appears at $166{ }^{\circ} \mathrm{C}$, positioned at the same temperature of the unexposed sample main peak.

Laminates show the same behaviour of tapes, even if melting temperature shift is lower, as highlighted in Fig. 5. Samples after $100 \mathrm{~h}$ (Fig. 4b, red curve) show a melting peak at $167^{\circ} \mathrm{C}\left(3^{\circ} \mathrm{C}\right.$ lower respect to unexposed samples). Specimens exposed for $250 \mathrm{~h}$ (Fig. 4b, blue curve) show a double feature (main melting peak at $160{ }^{\circ} \mathrm{C}$ and a secondary one at $165^{\circ} \mathrm{C}$ ); after $500 \mathrm{~h}$ (Fig. $4 \mathrm{~b}$, green curve) the main peak $\left(160^{\circ} \mathrm{C}\right)$ becomes more prominent while the secondary (still clearly visible at $165^{\circ} \mathrm{C}$ ) becomes less pronounced.

As underlined above and as noticeable in Fig. 5, PP melting peak shifts towards lower values at increasing exposure times. Chain scission, due to photo-degradation, occurs mainly in the amorphous region, but also at the lamellar fold surface, causing an increase of crystal surface free energy and a melting temperature decrease [26,38]. As above mentioned, melting temperature decrease is more pronounced in exposed tapes than in laminates, because chemical degradation is enhanced by internal stress [30].

The presence of a double peak in exposed sample thermographs is caused by the formation of small and defective molecules, like carbonyl and hydroperoxides groups, during the photodegradation process. These small molecules contribute to the
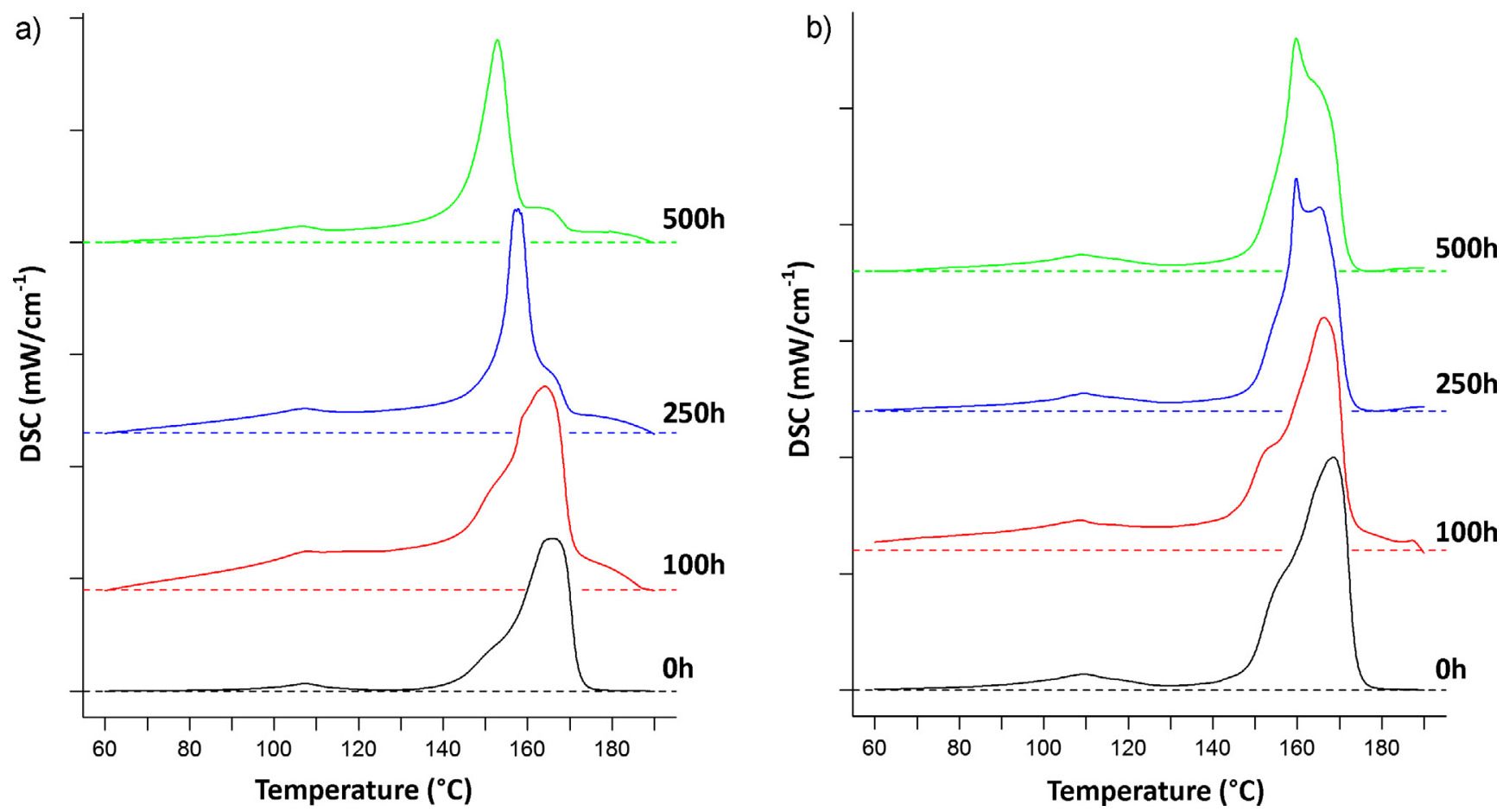

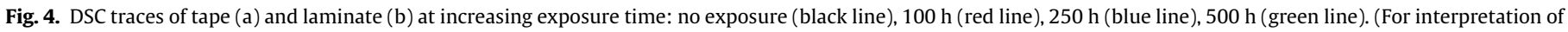
the references to colour in this figure legend, the reader is referred to the web version of this article.) 
recrystallisation process where imperfect and heterogeneous crystals are formed [38].

It is worth noticing that PE melting temperature $\left(107^{\circ} \mathrm{C}\right)$ remains constant over aging time for all samples.

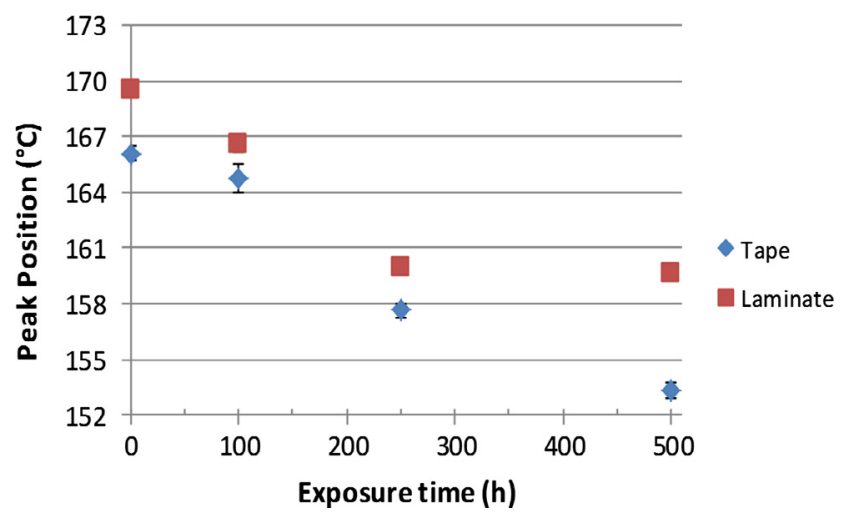

Fig. 5. Main melting peak position as a function of exposure time. (For interpretation of the references to colour in this figure legend, the reader is referred to the web version of this article.)

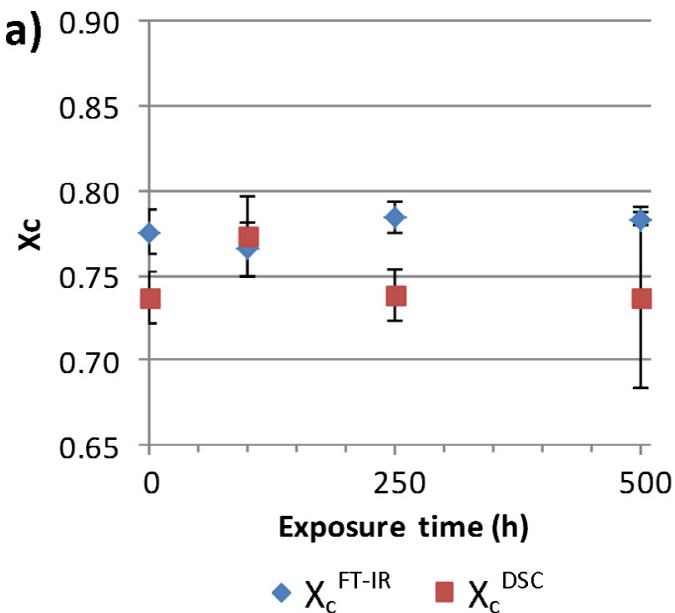

\subsection{Crystallinity evaluation}

Crystallinity calculated using Raman, DSC and FT-IR as a function of exposure time is shown in Figs. 6 and 7. Those values are reasonably comparable, since it has been already reported that crystallinity determination depends on the technique used $[35,39]$. It is noteworthy to mention that crystallinity values calculated using Raman spectroscopy are more affected by the material lack of homogeneity [37] because spectra are collected by means of a microscope objective, that analyses a smaller area than DSC and FT-IR. In addition, with Raman spectroscopy it is possible to estimate both crystalline phase $\left(X_{c}^{\text {Raman }}\right)$ and isomeric defect phase $\left(\mathrm{X}_{\mathrm{b}}^{\text {Raman }}\right)$, consisting of helical chains (Fig. 7).

The high PP crystallinity value for SRC has been already observed in a previous work [37], and its explanation is related to the high draw ratio applied during coextrusion of PP (core) and coPP/PE (skin), that causes a stretching-induced crystallisation [2].

The lower crystallinity value found for laminates can be ascribed to the portion of material that melts and becomes amorphous during the consolidation process conducted at $140{ }^{\circ} \mathrm{C}$. At increasing exposure time, this amorphous part can rearrange its structure and increase the overall crystallinity [26,27].

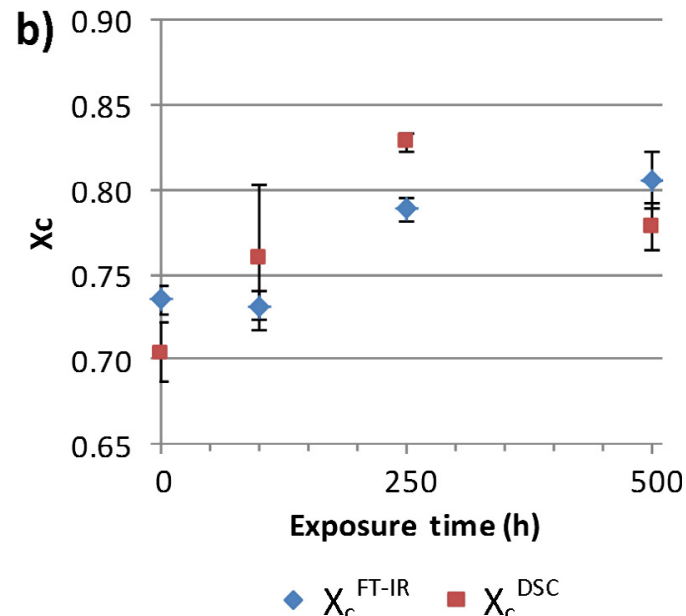

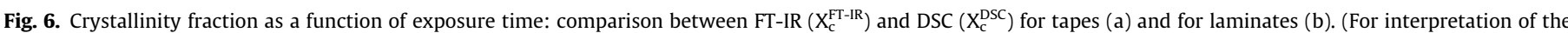
references to colour in this figure legend, the reader is referred to the web version of this article.)
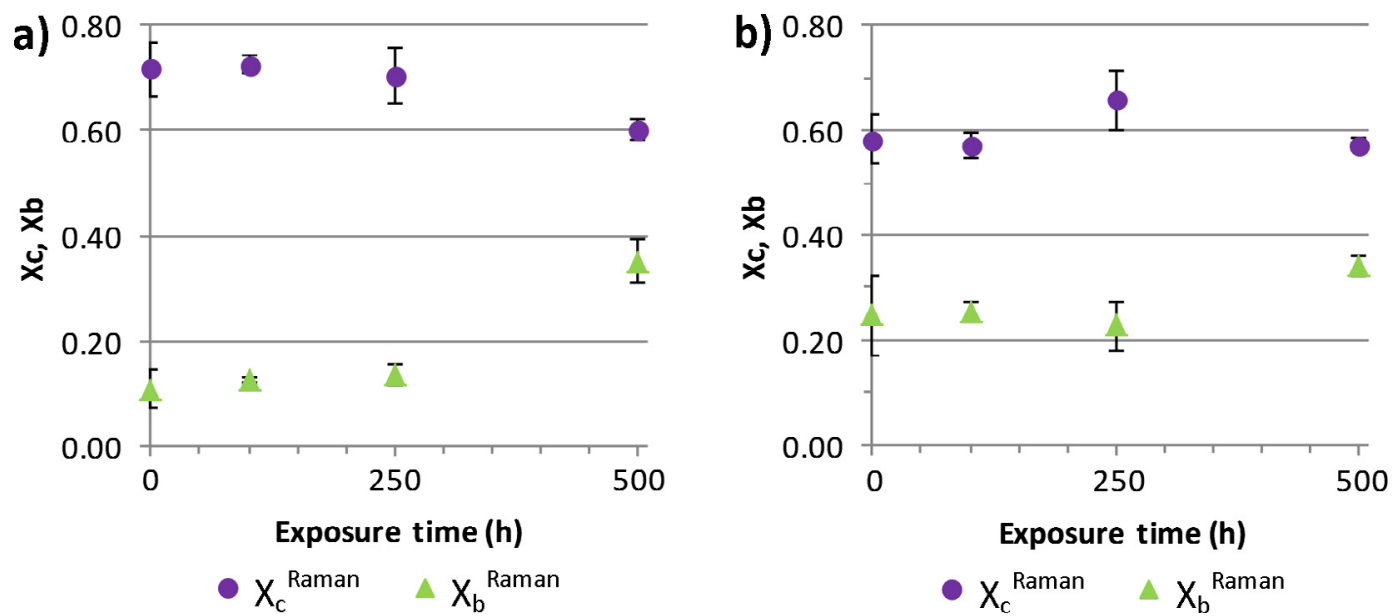

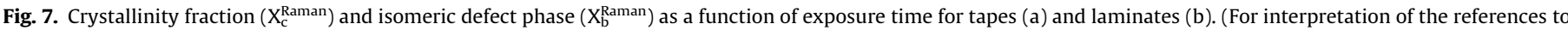
colour in this figure legend, the reader is referred to the web version of this article.) 
From FT-IR and DSC data, tape crystallinity (Fig. 6a) seems to be not affected by the exposure time, while laminate crystallinity increases after $100 \mathrm{~h}$ of exposure (Fig. 6b) reaching a constant value at $250 \mathrm{~h}$.

Tape $X_{c}^{\text {Raman }}$ decreases after 500 h of exposure, while the amount of isomeric defect phase increases (Fig. 7a). As above mentioned, laminate crystallinity before exposure is lower than tape, but the isomeric defect fraction $(0.25 \pm 0.08)$ is higher for laminate than for tape $(0.11 \pm 0.04)$. Hence the consolidation at $140{ }^{\circ} \mathrm{C}$ influences the amount of both crystalline and isomeric defect phase. During exposure laminate $X_{c}^{\text {Raman }}$ slightly increases until $250 \mathrm{~h}$ and then decreases; on the contrary the isomeric defect phase fraction $\left(\mathrm{X}_{\mathrm{b}}^{\mathrm{Raman}}\right.$ ) remains constant up to $250 \mathrm{~h}$ and then increases at $500 \mathrm{~h}$.

After prolonged exposure time the generation of impurity groups like carbonyls and hydroperoxides reduces the molecular regularity [27], limits the chemi-crystallisation and, as highlighted by Raman results, increases the isomeric defect fraction.

\section{Conclusions}

In this work the effect of artificial weathering on polypropylene tapes and laminates has been evaluated using differential scanning calorimetry, Fourier Transform Infrared spectroscopy and Raman spectroscopy. Samples morphological analysis after $500 \mathrm{~h}$ of exposure has highlighted the presence of surface cracks, more evident for laminate due to chemi-crystallisation of amorphous PP regions. FT-IR spectroscopy has revealed the presence of low molecular weight by-products characterized by carbonyl or hydroxyl/ hydroperoxide groups. In particular carbonyl index is higher for tapes than for laminates, especially after $100 \mathrm{~h}$ and $250 \mathrm{~h}$ of exposure, because of internal stress induced by drawing process.

DSC measurements have verified that PP melting peak shifts to lower values at increasing exposure time whereas PE melting temperature remains constant.

DSC and FT-IR results have demonstrated that while tape crystallinity is not affected by the exposure time, the greater amorphous phase present in laminates is able to rearrange its structure causing a rise in overall crystallinity. Furthermore, Raman spectroscopy has revealed that after prolonged exposure time, photo-degradation induces a rise of the isomeric defect fraction, limiting chemi-crystallisation both for tapes and laminates.

\section{Acknowledgments}

This work has been realized inside INDUSTRIA 2015 - Sustainable Mobility project funded by MISE (Italian Ministry of Economic Development) in which the authors would like to thank for financial support. All authors have contributed equally to this work.

\section{References}

[1] Kmetty Á, Bárány T, Karger-Kocsis J. Self-reinforced polymeric materials: a review. Prog Polym Sci 2010;35:1288-310. http://dx.doi.org/10.1016/j. progpolymsci.2010.07.002.

[2] Karger-Kocsis J, Bárány T. Single-polymer composites (SPCs): status and future trends. Compos Sci Technol 2014;92:77-94. http://dx.doi.org/10.1016/ i.compscitech.2013.12.006.

[3] Alcock B, Cabrera NO, Barkoula NM, Peijs T. The effect of processing conditions on the mechanical properties and thermal stability of highly oriented PP tapes. Eur Polym J 2009;45:2878-94. http://dx.doi.org/10.1016/j. eurpolymi.2009.06.025.

[4] Alcock B, Cabrera NO, Barkoula N-M, Loos J, Peijs T. Interfacial properties of highly oriented coextruded polypropylene tapes for the creation of recyclable all-polypropylene composites. J Appl Polym Sci 2007;104:118-29. http://dx. doi.org/10.1002/app.24588.

[5] Izer A, Bárány T, Varga J. Development of woven fabric reinforced allpolypropylene composites with beta nucleated homo- and copolymer matrices. Compos Sci Technol 2009;69:2185-92. http://dx.doi.org/10.1016/ j.compscitech.2009.06.002.
[6] Alcock B, Cabrera NO, Barkoula N-M, Loos J, Peijs T. The mechanical properties of unidirectional all-polypropylene composites. Compos Part Appl Sci Manuf 2006;37:716-26. http://dx.doi.org/10.1016/i.compositesa.2005.07.002.

[7] Alcock B, Cabrera NO, Barkoula N-M, Spoelstra AB, Loos J, Peijs T. The mechanical properties of woven tape all-polypropylene composites. Compos Part Appl Sci Manuf 2007;38:147-61. http://dx.doi.org/10.1016/ j.compositesa.2006.01.003.

[8] Alcock B, Cabrera NO, Barkoula N-M, Wang Z, Peijs T. The effect of temperature and strain rate on the impact performance of recyclable all-polypropylene composites. Compos Part B Eng 2008;39:537-47. http://dx.doi.org/10.1016/ j.compositesb.2007.03.003.

[9] Richaud E, Farcas F, Fayolle B, Audouin L, Verdu J. Hydroperoxide build-up in the thermal oxidation of polypropylene - a kinetic study. Polym Degrad Stab 2007;92:118-24. http://dx.doi.org/10.1016/j.polymdegradstab.2006.08.010.

[10] Celina MC. Review of polymer oxidation and its relationship with materials performance and lifetime prediction. Polym Degrad Stab 2013;98:2419-29. http://dx.doi.org/10.1016/i.polymdegradstab.2013.06.024.

[11] Fernando SS, Christensen PA, Egerton TA, White JR. Humidity dependence of carbon dioxide generation during photodegradation of biaxially oriented polypropylene in oxygen. Polym Degrad Stab 2009;94:83-9. http://dx.doi.org/ 10.1016/i.polymdegradstab.2008.10.007.

[12] Deng H, Reynolds CT, Cabrera NO, Barkoula N-M, Alcock B, Peijs T. The water absorption behaviour of all-polypropylene composites and its effect on mechanical properties. Compos Part B Eng 2010;41:268-75. http://dx.doi. org/10.1016/i.compositesb.2010.02.007.

[13] Alcock B, Cabrera NO, Barkoula N-M, Peijs T. Low velocity impact performance of recyclable all-polypropylene composites. Compos Sci Technol 2006;66:1724-37. http://dx.doi.org/10.1016/i.compscitech.2005.11.010.

[14] Rosa DS, Angelini JMG, Agnelli JAM, Mei LHI. The use of optical microscopy to follow the degradation of isotactic polypropylene (iPP) subjected to natural and accelerated ageing. Polym Test 2005;24:1022-6. http://dx.doi.org/ 10.1016/j.polymertesting.2005.07.009.

[15] Turton TJ, White JR. Observation of different photo-degradation behaviour in two similar polypropylenes. J Mater Sci 2001;36:4617-24.

[16] Gallo R, Severini F. Course of the changes in thick and thin isotactic polypropylene samples subjected to natural aging. Polym Degrad Stab 2013;98:1144-9. http://dx.doi.org/10.1016/i.polymdegradstab.2013.03.017.

[17] Yakimets I, Lai D, Guigon M. Effect of photo-oxidation cracks on behaviour of thick polypropylene samples. Polym Degrad Stab 2004;86:59-67. http://dx. doi.org/10.1016/i.polymdegradstab.2004.01.013.

[18] Aslanzadeh S, Kish MH. Photo-oxidation of polypropylene fibers exposed to short wavelength UV radiations. Fibers Polym 2010;11:710-8.

[19] Fernando SS, Christensen PA, Egerton TA, White JR. Carbon dioxide evolution and carbonyl group development during photodegradation of polyethylene and polypropylene. Polym Degrad Stab 2007;92:2163-72. http://dx.doi.org/ 10.1016/j.polymdegradstab.2007.01.032.

[20] Gallo R, Brambilla L, Castiglioni C, Ipsale S, Severini F, Quasso F, et al. Environmental degradation of a novel ethylene-propylene copolymer in thick sheets. Eur Polym J 2005;41:359-66. http://dx.doi.org/10.1016/i. eurpolymi.2004.09.014.

[21] Arruebarrena de Báez M. Hendra PJ, Judkins M. The Raman spectra of oriented isotactic polypropylene. Spectrochim Acta A Mol Biomol Spectrosc 1995;51:2117-24. http://dx.doi.org/10.1016/0584-8539(95)01512-1.

[22] Gen DE, Prokhorov KA, Nikolaeva GY, Sagitova EA, Pashinin PP, Shklyaruk BF, et al. Raman spectra of various polymorphs of isotactic polypropylene. Laser Phys 2011;21:125-9. http://dx.doi.org/10.1134/S1054660X11020010.

[23] Blakey I, George GA. Raman spectral mapping of photo-oxidised polypropylene. Polym Degrad Stab 2000;70:269-75.

[24] White JR, Shyichuk AV. Macromolecular scission and crosslinking rate changes during polyolefin photo-oxidation. Polym Degrad Stab 2007;92:1161-8. http://dx.doi.org/10.1016/i.polymdegradstab.2007.04.011.

[25] Shyichuk AV, White JR, Craig IH, Syrotynska ID. Comparison of UV-degradation depth-profiles in polyethylene, polypropylene and an ethylene-propylene copolymer. Polym Degrad Stab 2005;88:415-9. http://dx.doi.org/10.1016/j. polymdegradstab.2004.12.006.

[26] Rabello MS, White JR. The role of physical structure and morphology in the photodegradation behaviour of polypropylene. Polym Degrad Stab 1997:56:55-73.

[27] Rabello MS, White JR. Crystallization and melting behaviour of photodegraded polypropylene-I. Chemi-crystallization. Polymer 1997;38:6379-87.

[28] Rabello MS, White JR. Crystallization and melting behaviour of photodegraded polypropylene-II. Re-crystallization of degraded molecules. Polymer 1997;38:6389-99.

[29] Shyichuk AV, Stavychna DY, White JR. Effect of tensile stress on chain scission and crosslinking during photo-oxidation of polypropylene. Polym Degrad Stab 2001;72:279-85.

[30] Kelly CT, White JR. Photo-degradation of polyethylene and polypropylene at slow strain-rate. Polym Degrad Stab 1997;56:367-83.

[31] Ferluga A, Caniato M, Sbaizero O. The influence of consolidation and artificial weathering on all-PP composite behavior. J Appl Polym Sci 2015;132:41283. http://dx.doi.org/10.1002/app.41283.

[32] Beleites C, Sergo V. hyperSpec: a package to handle hyperspectral data sets in R; n.d.

[33] R Core Team. R: A language and environment for statistical computing. R Foundation for Statistical Computing, Vienna; 2013. 
[34] Wojdyr M. Fityk: a general-purpose peak fitting program. J Appl Crystallogr 2010;43:1126-8. http://dx.doi.org/10.1107/S0021889810030499.

[35] Nielsen AS, Batchelder DN, Pyrz R. Estimation of crystallinity of isotactic polypropylene using Raman spectroscopy. Polymer 2002;43:2671-6.

[36] Karacan I, Benli $H$. The influence of annealing treatment on the molecular structure and the mechanical properties of isotactic polypropylene fibers. J Appl Polym Sci 2011;122:3322-38. http://dx.doi. org/10.1002/app.34440.
[37] Marsich L, Ferluga A, Venturini N, Caniato M, Sbaizero O, Schmid C. The morphological properties of PP coextruded tape fabrics. Polym Eng Sci. 2016: n/a-a. http://dx.doi.org/10.1002/pen.24299.

[38] Fechine GJM, Demarquette NR. Cracking formation on the surface of extruded photodegraded polypropylene plates. Polym Eng Sci. 2008;48:365-72. http:// dx.doi.org/10.1002/pen.20958.

[39] Lin W, Cossar M, Dang V, Teh J. The application of Raman spectroscopy to three-phase characterization of polyethylene crystallinity. Polym Test 2007;26:814-21. http://dx.doi.org/10.1016/j.polymertesting.2007.05.004. 